\title{
Principles for Management of Intraoperative Acute Type A Aortic Dissection
}

\author{
Philemon Gukop, MBBS, MRCS* , Vankatachalam Chandrasekaran, MD, FRCS(CTh) \\ Department of Cardiothoracic Surgery, St George's Hospital NHS Trust, London, United Kingdom
}

\begin{abstract}
Intraoperative Type A aortic dissection is a rare pathology with incidence of $0.06-0.32 \%$. It is associated with a high mortality between $\mathbf{3 0 - 5 0 \%}$. Some associated risk factors, including hypertension, enlarged aorta, peripheral vascular disease, advanced age, atheroma, and high arterial pressure on cardiopulmonary bypass, have been identified. Modification of these risk factors could reduce the incidence of this event. Prompt diagnosis and management, with the aid of intraoperative trans-esophageal echocardiography and/or epi-aortic ultrasound has been shown to reduce the mortality to $17 \%$. We illustrate the principles of management of this pathology with the case of a 62-year-old female who developed acute Type $A$ aortic dissection while undergoing minimally invasive mitral valve repair.

Copyright @ 2015 Science International Corp.
\end{abstract}

\section{Key Words}

Aortic dissection - Aortic operation - Surgical complications • Practice guidelines (aorta) • Perioperative care

\section{Introduction}

Intraoperative or iatrogenic Type A aortic dissection is a very rare but important pathology with an incidence of 0.06 to $0.32 \%$ [1, 2]. It has a high mortality of between 30 to 50\% [3]. Early detection and prompt treatment has been shown to reduce its mortality to about $17 \%$ [1]. It is associated with high morbidity and often requires further surgery. Its risk

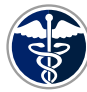

Fax +1 2037853552

E-Mail: aorta@scienceinternational.org

http://aorta.scienceinternational.org

\author{
() 2015 AORTA \\ Published by Science International Corp. \\ ISSN 2325-4637 \\ Accessible online at: \\ http://aorta.scienceinternational.org
}

factors are known. All cardiovascular surgeons should be aware of its risk factors and have immediately in mind a strategy for prompt identification and management. We illustrate the management principles of this pathology with the case of a 62-year-old female admitted for mitral valve repair.

\section{Case Presentation}

A 62-year-old female presented with sudden onset, shortness of breath, and chest pain. Further investigation showed severe mitral regurgitation due to chordae rupture with a dilated aortic root measuring $4.0 \mathrm{~cm}$ and trivial aortic regurgitation with a trileaflet aortic valve. Her past medical history was remarkable for paroxysmal atrial fibrillation and hypertension but no history of steroid use or connective tissue disorder.

She had unobstructed coronary arteries and was referred for urgent mitral valve repair.

She had an uneventful general anesthesia for minimally invasive mitral valve repair. There was fluctuation in her blood pressure during femoral artery cannulation for the initiation of cardiopulmonary bypass and trans-esophageal echocardiography showed features of Type A acute aortic dissection.

The operation was converted to full sternotomy. Ascending aortic cannulation was secured and the arterial line transferred from the femoral site. The hemodynamics were stable with blood pressure of $50-60 \mathrm{~mm} \mathrm{Hg}$. After cooling to $18^{\circ} \mathrm{C}$, the pump

* Corresponding Author:

Philemon Gukop, MBBS, MRCS

Department of Cardiothoracic Surgery,

St George's Hospital NHS Trust,

Blackshaw Rd., London SW17 0QT, UK

Tel: +44 0 2087253962; Fax: +44 0 2087252170; E-Mail: gukop@doctors.org.uk 

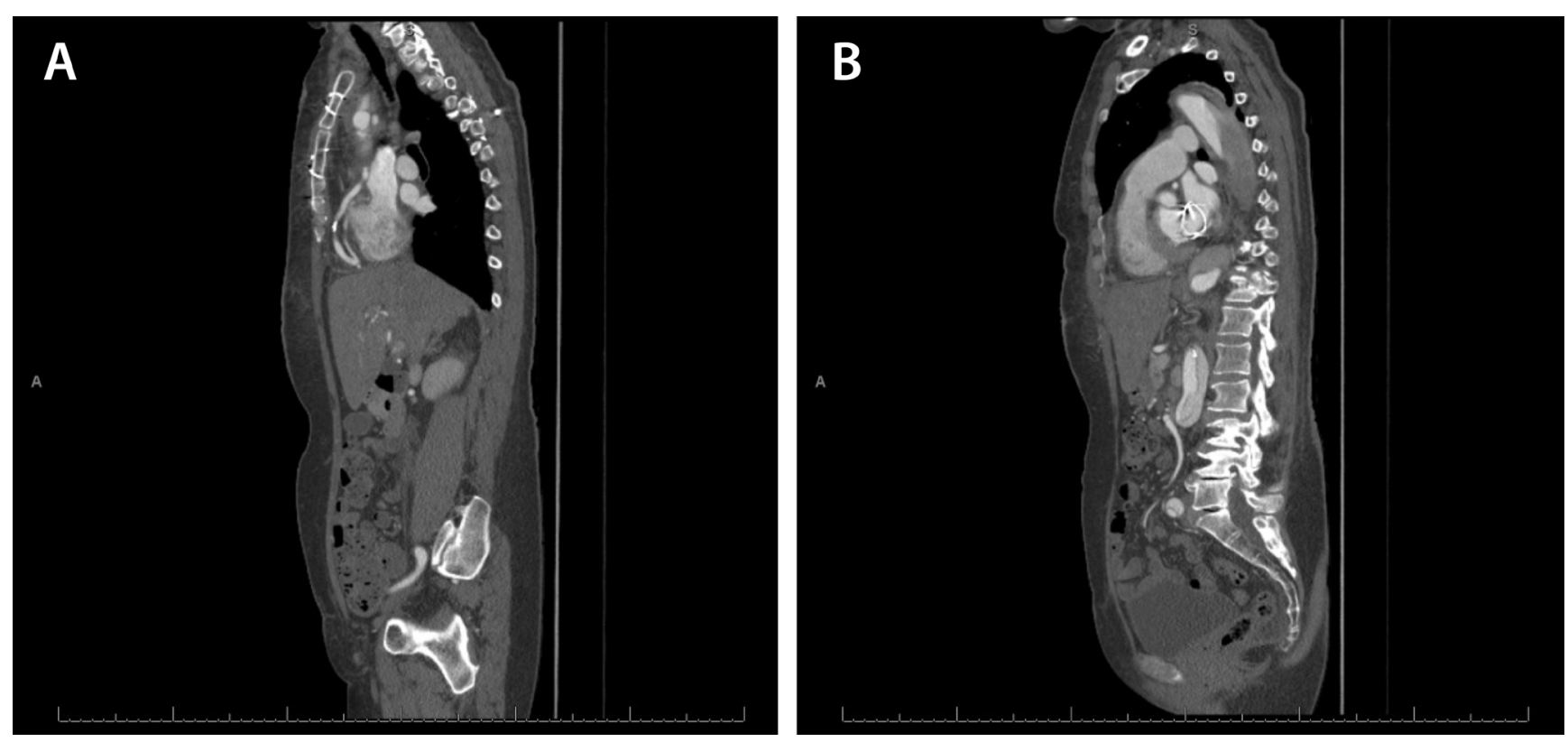

Figure 1. Computerized tomography scan postopeartively showing ascending aorta with hemi-arch replacement, mitral valve repair, and vein graft to right coronary artery (Panel $A)$ and residual aortic arch dissection. (Panel B)

was stopped and cannulation site changed. Via aortobicaval cannulation, she underwent uneventful mitral valve repair with Capentier Edward's 38-mm mitral annuloplasty ring and two neo-chodea to P2 with Gortex sutures via inter-atrial sulcus approach; the ascending aorta was replaced up to the hemi-arch with $30-\mathrm{mm}$ Hemashield graft. A period of deep hypothermic circulatory arrest at $18^{\circ} \mathrm{C}$ was required for the aortic anastomosis. There was difficulty in weaning off bypass with some ischemic changes on the inferior electrocardiogram leads. A saphenous vein coronary artery bypass graft to right coronary artery facilitated weaning off cardiopulmonary bypass and resolution of ischemia.

She made a good and uneventful recovery. Histology of aorta showed cystic medial necrosis. Postoperative Computed tomographic (CT) aortogram on day 2 (Figure 1) showed residual aortic dissection extending from the proximal aortic arch down to and involving both iliac arteries. There was no compromise of any of the aortic branches. She was followed up with serial echocardiogram and CT aortogram. Three years postoperatively, there was a significant increase in the diameter of the aortic arch to $5.5 \mathrm{~cm}$, extending to the proximal descending thoracic aorta. The residual aortic dissection was electively repaired by replacement of the aortic arch with a 30-mm Hemashield graft using the elephant trunk technique under deep hypothermic circulatory arrest (DHCA) at $18^{\circ} \mathrm{C}$. A 4-mm tear was found at the junction of the distal aortic arch and descending aorta probably from the previous dissection. There was a false lumen in the native aorta partially covering the innominate origin and extending into the distal arch. The innominate and left carotid arteries were re-implanted into the graft on an island of tissue, while the subclavian artery was left in situ. The innominate and left carotid arteries were cannulated with a cardioplegia cannula and used for antegrade cerebral perfusion at $10 \mathrm{ml} / \mathrm{kg}$. The distal arch was divided between the left carotid and subclavian arteries circumferentially. The intimal tear distal to this site was closed with two pladgeted horizontal mattress sutures. At the completion of the graft to island anastomosis, the neck vessel cannulae were removed carefully, de-aired, and then the circulation through the aortic arch was commenced to the entire body except the heart. The proximal end of the graft tube was sutured to the previous tube graft. Complete circulation was recommenced, including perfusion of the heart. She again made a good and uneventful recovery from the operation. The residual stable dissection in the distal descending thoracic aorta is been managed conservatively and monitored with serial CT scans (Figure 2) [2]. 

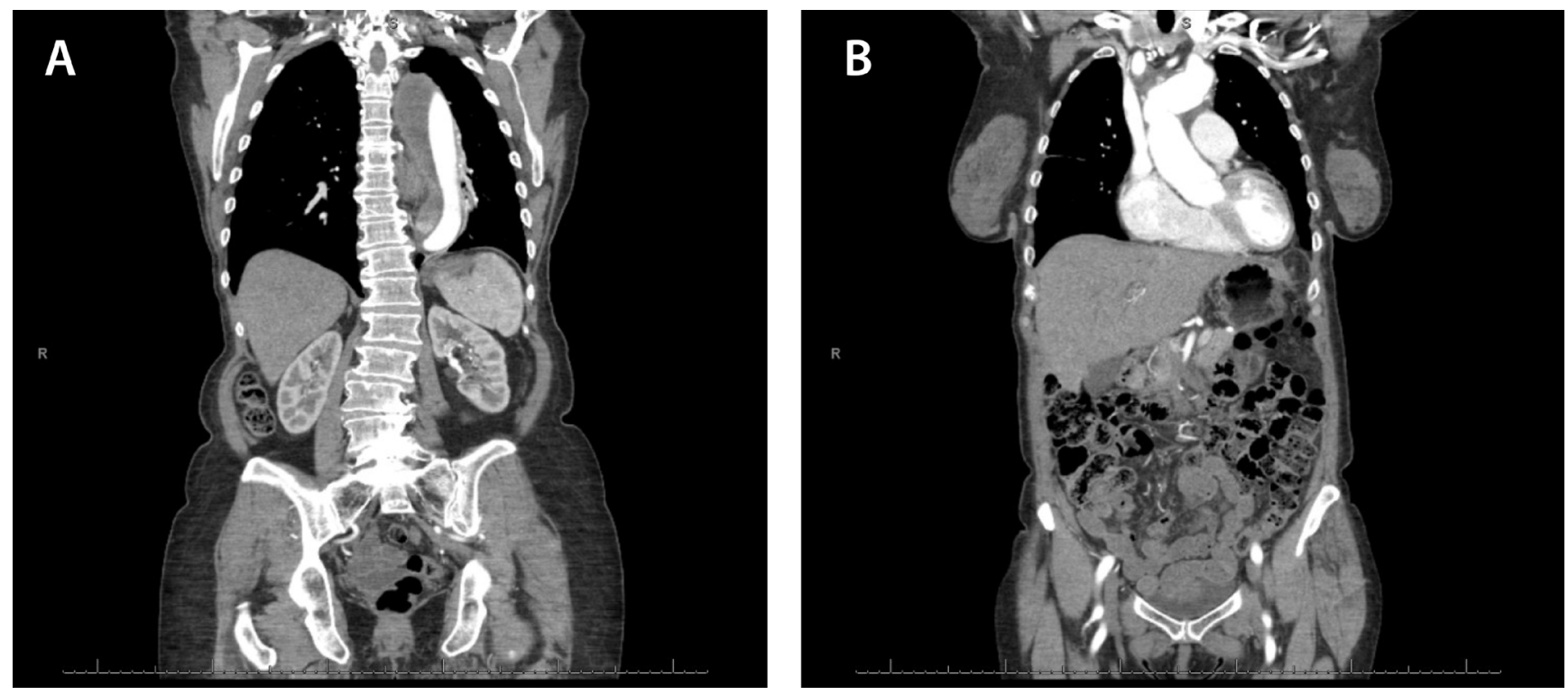

Figure 2. Computerized Tomography aorta showing staged replacement of ascending aorta and arch (Panel B) with residual stable descending aorta dissection (Panel A)

\section{Discussion}

latrogenic Type $\mathrm{A}$ aortic dissection is a very rare but important pathology with an incidence of 0.06 to $0.32 \%[3,4]$. It has a high mortality of between 30 to $50 \%$ [5]. Early detection and prompt treatment has been shown to reduce its mortality to about 17\% [1]. Proper anesthetic strategy of hypotension and DHCA have also been shown to enhance outcome $[1,6]$.

Risk factors for intraoperative Type $A$ aortic dissection have been identified (Table 1). These include hypertension, peripheral vascular disease, advanced age ( $>65$ years), large diameter of the aorta, use of steroid, pre-existing aortic pathology, femoral arterial cannulation, and high cardiopulmonary bypass pressures greater than $120 \mathrm{~mm} \mathrm{Hg}[3,5,7]$.

Intraoperative Type A aortic dissection is potentially fatal and thus essential that all cardiovascular surgeons are aware of this entity, including its risk factors, strategy for prompt identification, and management options.

Our case demonstrates a patient with identifiable risk factors for intraoperative Type A aortic dissection, namely hypertension and enlarged aorta. Also, intraoperatively, she had a period of hypertension during femoral cannulation. The immediate availability of intraoperative tranoesophageal echocardiography facilitated a prompt diagnosis of the pathology [8]. Prompt

Gukop, P. et al. strategy of immediate repair of the dissection via sternotomy and alternative arterial cannulation site with DHCA facilitated a good outcome for the patient [9].

Intraoperative Type A aortic dissection has been reported in all types of cardiac surgery including off pump coronary artery bypass surgery. All arterial cannulation sites have been identified as possible initiation sites [1]. Precipitating factors include arterial cannulation, aortic cross clamp application, and removal of the arterial cannula [7].

Table 1. Risk factors for latrogenic Type A aortic dissection.

Preoperative steroids

Femoral cannulation

Enlarged ascending aorta $(\geq 4.0 \mathrm{~cm})$

Hypertension

Peripheral vascular disease

Advance age ( $\geq 70$ years)

Asian race

Female gender

High cardiopulmonary bypass pressure (>120 mm Hg)

Connective tissue disease

Aortic pathology (aortitis)

Arteriosclerosis 
Intraoperative trans-esophageal echocardiography (TEE) and/or epi-aortic ultrasound are the gold standards for prompt diagnosis of intraoperative aortic dissection, although clinical observation is also essential $[1,10]$. Dissection is easily identified by blue discoloration and expansion of the ascending aorta, intractable bleeding from aortic sites, and high perfusion line pressures with associated systemic hypotension. Once dissection is identified, separation from cardiopulmonary bypass and pursuit of an alternative cannulation site with repair of the aortic dissection under DHCA is the optimal treatment strategy. Blood pressure of less than $50 \mathrm{~mm} \mathrm{Hg}$ during change of cannulation site is associated with poor outcome [4]. Transapical aortic cannulation is a reasonable option in this situation [11].

Risk factor modifications include avoiding cannulation of significantly diseased arterial sites, avoiding clamping of a highly pressurized aorta, torqueing of partial occlusion clamp, and minimal or gentle handling of the aorta may discourage the occurrence of this pathology.
We suggest that all patients with identifiable risk factors for intraoperative Type A aortic dissection should have intraoperative TEE monitoring and risk factor modification strategy during any cardiac surgery. This will facilitate prompt identification and treatment with significant reduction in mortality [1].

Intraoperative Type A aortic dissection is a rare but important pathology with high morbidity and mortality. Identifiable risk factors can be managed to discourage its occurrence. Prompt identification of intraoperative aortic dissection by intraoperative TEE has been shown to enhance outcomes.

\section{Conflict of Interest}

The authors have no conflicts of interest relevant to this publication.

\section{Comment on this Article or Ask a Question}

\section{References}

1. Hwang $H Y$, Jeong DS, Kim $\mathrm{KH}$, Kim KB, Ahn $\mathrm{H}$. latrogenic type $A$ aortic dissection during cardiac surgery. Interact Cardiovasc Thorac Surg. 2010;10:896-899. DOI: 10.1510/icvts.2009.231001

2. Hiratzka LF, Bakris GL, Beckman JA, Bersin RM, Carr VF, Casey DE, Jr., et al. 2010 ACCF/AHA/AATS/ACR/ASA/SCA/SCAI/ SIR/STS/SVM guidelines for the diagnosis and management of patients with Thoracic Aortic Disease: A report of the American College of Cardiology Foundation/ American Heart Association Task Force on Practice Guidelines, American Association for Thoracic Surgery, American College of Radiology, American Stroke Association, Society ofCardiovascular Anesthesiologists, Society for Cardiovascular Angiography and Interventions, Society of Interventional Radiology, Society of Thoracic Surgeons, and Society for Vascular Medicine. Circulation. 2010;121:e266-369. DOI: 10.1161/CIR.0b013e3181d4739e

3. Williams ML, Sheng S, Gammie JS, Rankin JS, Smith PK, Hughes GC. Richard E. Clark Award. Aortic dissection as a complication of cardiac surgery: report from the Society of Thoracic Surgeons database. Ann Thorac Surg. 2010;90:1812-1817. DOI: 10.1016/j. athoracsur.2010.05.023
4. Fleck $T$, Ehrlich $M$, Czerny $M$, Wolner $E$, Grabenwoger M, Grimm M. Intraoperative iatrogenic type A aortic dissection and perioperative outcome. Interact Cardiovasc Thorac Surg. 2006;5:11-14. DOI: 10.1510/icvts.2005.114900

5. Leontyev S, Borger MA, Legare JF, Merk D, Hahn J, Seeburger J, et al. latrogenic type A aortic dissection during cardiac procedures: early and late outcome in 48 patients. Eur J Cardiothorac Surg. 2012;41:641-646. DOI: $10.1093 /$ ejcts/ezr070

6. Kubota $Y$, Kamei M, Tomita Y, Miyazaki A, Miyake E, Ohnishi Y. [Anesthetic management of intraoperative aortic dissection during cardiovascular surgery]. Masui Japan J Anesthesiol. 2014;63: 143-148.

7. Ketenci B, Enc Y, Ozay B, Gunay R, Cimen S, Gorur A, et al. Perioperative type I aortic dissection during conventional coronary artery bypass surgery: risk factors and management. Heart Surg Forum. 2008;11:E231-236. DOI: 10.1532/ HSF98.20081032

8. Assaad S, Geirsson A, Rousou L, Sherman B, Perrino $A$. The dual modality use of epiaortic ultrasound and transesophageal echocardiography in the diagnosis of intraoperative iatrogenic type-a aortic dissection.
J Cardiothorac Vasc Anesth. 2013;27: 326-328. DOI: 10.1053/j.jvca.2011.09.026

9. Rylski B, Hoffmann I, Beyersdorf $F$, Suedkamp $M$, Siepe $M$, Nitsch $B$, et al. latrogenic acute aortic dissection type $A$ : insight from the German Registry for Acute Aortic Dissection Type A (GERAADA). Eur J Cardiothorac Surg. 2013;44:353-359. DOI: 10.1093/ejcts/ezt055

10. Yen $C M$, Hung $C J$, Chen KB, Chang CC, Wu RS. Latrogenic aortic dissection during mitral valve replacement surgery-a case report. Acta Anaesthesiologica Taiwanica. 2005;43:253-256. PMID: 16450602

11. Matsushita A, Manabe S, Tabata M, Fukui T, Shimokawa T, Takanashi S. Efficacy and pitfalls of transapical cannulation for the repair of acute type A aortic dissection. Ann Thorac Surg. 2012;93:1905-1909. DOI: 10.1016/j.athoracsur.2012.02.036

Cite this article as: Gukop $P$, Chandrasekaran V. Principles for Management of Intraoperative Acute Type A Aortic Dissection. AORTA (Stamford). 2015;3(6):191-194. DOI: http://dx.doi.org/10.12945/j.aorta. 2015.15.007 